\title{
UNASUR SALUD: EXPERIENCIAS Y DEBATES AL FINAL DE UN CICLO
}

\section{UNASUR HEALTH: EXPERIENCES AND DEBATES AT THE END OF A CYCLE}

\author{
Marco Narea \\ Daniele Benzi
}

\begin{abstract}
RESUMEN
La creación del Consejo de Salud Suramericano (CSS o UNASUR Salud) abrió un espacio político e institucional innovador para el debate regional en esta materia. Bajo el impulso del gobierno de Brasil, UNASUR Salud y el Instituto Suramericano de Gobierno en Salud (ISAGS) promovieron la discusión sobre un pensamiento sanitario regional y el establecimiento de políticas comunes. No obstante, pese al vigor inicial y a algunos logros parciales, el CSS ya mostraba señales de estancamiento cuando la llegada al poder de gobiernos antitéticos al tipo de regionalismo promovido por la UNASUR terminaría exacerbando los problemas internos, quedándose desarmado a mediados de 2019. Así, cuando la Organización Mundial de la Salud (OMS) declaró al Covid-19 como pandemia en marzo de 2020, UNASUR Salud ya no tenía capacidad de respuesta. El artículo propone un recuento de la trayectoria del Consejo de Salud apoyado en la revisión de documentación oficial y literatura especializada; busca destacar críticamente logros y limitaciones del CSS haciendo hincapié en el rol de Brasil y; finalmente, abre el debate sobre la falta de respuestas comunes entre los gobiernos suramericanos frente a la pandemia del Covid-19.
\end{abstract}

\section{PALABRAS CLAVE}

Regionalismo; Brasil; UNASUR Salud; ISAGS.

\begin{abstract}
The South American Health Council (CSS, by its acronym in Spanish, or UNASUR Health) opened an innovative political and institutional space on health issues at a regional scale. Driven by the Brazilian government, UNASUR Health and the South American Institute of Government on Health (ISAGS, by its acronym in Spanish) promoted debates about a regional thinking and common policies on this subject. Nevertheless, despite some initial dynamism and achievements, the CSS had already been showing a slowdown when the coming to power of governments antithetical to UNASUR exacerbated its internal problems. UNASUR Health finally came to a virtual end by mid-2019. Consequently, when the World Health Organization (WHO) declared Covid-19 as a pandemic in March 2020, UNASUR Health had no capacity to take action. Drawing on official documents and specialized literature, this paper offers an analysis of the CSS. It highlights the achievements and deficiencies of UNASUR Health, stressing the role of the Brazilian government. Lastly, it opens the discussion regarding the lack of a common response to the Covid-19 pandemic among the South American governments.
\end{abstract}

\section{KEYWORDS}

Regionalism; Brazil; UNASUR Health; ISAGS. 


\section{INTRODUCCIÓN}

En la primera década de este siglo, en el marco de lo que fue denominado como "giro a la izquierda", la preocupación por la salud volvió a ser un tema prioritario en la agenda de los gobiernos progresistas, tanto nacional como regionalmente. Ello fue evidente en el incremento del gasto público estatal y en el despliegue de numerosas iniciativas de cooperación Sur-Sur en el ámbito latinoamericano e internacional. Entre las primeras destacan ciertamente aquellas encabezadas por los gobiernos de Venezuela y Cuba en el marco de la Alianza Bolivariana para los Pueblos de Nuestra América (ALBA) (Benzi, 2017, pp. 59-77), y las de Brasil a partir de las sinergias entre ministerios, escuelas, fundaciones, agencias e institutos nacionales, en ocasiones con el acompañamiento de la Organización Panamericana de la Salud (OPS) (Gayard, 2016, pp. 99-157).

La creación del Consejo de Salud Suramericano (CSS o UNASUR Salud) de la Unión de Naciones Suramericanas (UNASUR) se insertó, por tanto, en una coyuntura en la que la llegada al poder de los gobiernos progresistas revitalizó esta agenda como parte esencial de una agenda social más amplia, inherente al nuevo ciclo de regionalismo caracterizado como "posliberal" (Sanahuja, 2008) o "poshegemónico" (Riggirozzi y Tussie, 2012) ${ }^{1}$. Es así que desde 2008 el CSS constituyó la expresión política e institucional de los Estados miembros de la UNASUR para consolidar una agenda común en este campo.

La creación en el interior del CSS del Instituto Suramericano de Gobierno en Salud (ISAGS), por impulso del gobierno de Brasil, fue un puntal clave del accionar de este consejo. En él se llevaron a cabo de manera sobresaliente algunos debates en torno a la construcción de un pensamiento sanitario suramericano y la formulación de estrategias y políticas regionales en salud.

\footnotetext{
${ }^{1}$ La región ya contaba con acuerdos de cooperación subregionales en materia de salud. No obstante, este tipo de experiencias "se vieron limitadas por necesidades -reales o percibidas- de ajuste estructural y reducción del gasto social en la década del noventa” (Riggirozzi, 2015a, p. 41, traducción de los autores). Ejemplos de ello son el Organismo Andino de Salud - Convenio Hipólito Unanue (ORAS-CONHU) de la Comunidad Andina, vigente desde 1971; la Coordinación de Salud de la Organización del Tratado de Cooperación Amazónica (OTCA), en funcionamiento desde 1978; y la Reunión de Ministros de Salud y el Subgrupo de Trabajo de Salud (SGT11) del MERCOSUR, establecidos en 1996.
} 
Pese a los proyectos en marcha y a los importantes consensos logrados al interior del consejo, las tensiones políticas entre los gobiernos de los Estados miembros terminaron por afectar su dinámica. Si bien el CSS puso en marcha la iniciativa de un Banco de Precios de Medicamentos tras años de negociación y, en el ámbito multilateral, logró presentar en reiteradas ocasiones posiciones comunes ante el principal foro en su materia: la Asamblea Mundial de la Salud (AMS), estos consensos se vieron interrumpidos a partir de 2017. De igual manera, pese al reflujo de la cooperación internacional brasileña en salud de la cual el ISAGS fue el resultado, éste logró desarrollar sus actividades durante unos años en una relativa inercia institucional. Sin embargo, debido al proceso de salida de la UNASUR que varios gobiernos empezaron en 2018 y a la falta de financiamiento, el ISAGS terminó suspendiendo sus actividades en junio de 2019. Es así que, cuando la Organización Mundial de la Salud (OMS) declaró al Covid-19 como pandemia en marzo de 2020, UNASUR Salud se encontraba ya sin capacidad de respuesta.

El artículo repasa en primer lugar la creación y estructura institucional del Consejo de Salud de la UNASUR. Seguidamente, analiza la experiencia de éste en la construcción de un pensamiento sanitario regional y la formulación de políticas regionales; su posicionamiento ante la AMS de la OMS y el destacado empuje brasileño a esta agenda regional. A manera de cierre, reflexiona brevemente sobre la llegada del Covid-19 a la región en una coyuntura de fragmentación y aparentemente impotencia de los principales esquemas de integración. A través de este recorrido, el principal cometido del artículo es estudiar el legado de una experiencia muy importante para la región, manteniendo vivo el debate sobre sus aportes y elementos críticos ante una deseable reanudación en el futuro.

El análisis es esencialmente de tipo cualitativo y se apoya en una extensa revisión de documentación oficial y literatura especializada, en el marco de un proyecto de investigación más amplio sobre la UNASUR como experiencia de un nuevo regionalismo suramericano a inicios del siglo XXI.

\section{ORIGEN Y ESTRUCTURA INSTITUCIONAL DEL CSS}

EI CSS fue creado durante la cumbre extraordinaria de la UNASUR llevada a cabo en diciembre de 2008, en Salvador de Bahía, mediante la Decisión para el Establecimiento del Consejo de Salud Suramericano de la UNASUR (2008). Esta decisión, que tiene calidad de estatuto, 
expresaba la voluntad de los gobiernos miembros de crear un órgano regional permanente de consulta y consenso con la finalidad de "[c]onsolidar Suramérica como un espacio de integración en Salud que contribuya a la Salud para Todos y al desarrollo, incorporando e integrando los esfuerzos y logros subregionales de MERCOSUR, ORAS CONHU y OTCA" (art. 5).

En aquella ocasión se acordó conformar un comité coordinador, una secretaría técnica y cinco grupos técnicos cuyas atribuciones fueron definidas en abril de 2009 en Santiago de Chile (Acuerdo UNASUR/Consejo de Salud Suramericano/Acuerdo No 01/09 - 21/04/2009, 2009). Junto a ello, se acordó también impulsar al consejo a través de la Agenda Suramericana de Salud/Plan de Trabajo 2009-2010 (2009), la cual estaba dividida en cinco áreas: 1) escudo epidemiológico; 2) desarrollo de los sistemas de salud universales; 3) acceso universal a medicamentos; 4) promoción de la salud y acción sobre los determinantes sociales y; 5) desarrollo y gestión de recursos humanos en salud. Estas áreas de trabajo agruparon un total de 18 actividades y fueron tomadas como base para la creación de cinco grupos técnicos bajo la coordinación de diferentes países (2009; Acuerdo UNASUR/Consejo de Salud Suramericano/Acuerdo $N^{\circ}$ 01/09 - 21/04/2009, 2009).

Asimismo, por iniciativa brasileña, se propuso la creación de una Escuela Suramericana de Salud. Es así que durante la III Reunión Extraordinaria del CSS, por consenso, se creó el Instituto Suramericano de Gobierno en Salud (Resolución 05/2009 del CSS, 2009). Desde entonces, el instituto canalizaría buena parte de las tareas del CSS, convirtiéndose en el "portavoz de UNASUR Salud" (Ventura, 2013, p. 106, traducción de los autores). El consejo resolvió también la necesidad de formular un Plan Quinquenal 2010-2015 con el apoyo de los grupos técnicos recién creados (Resolución 01/2009 del CSS, 2009) que, tras una etapa de elaboración participativa, fue aprobado en abril de 2010 (pp. 34-35). Fueron acordados cinco objetivos estratégicos, 28 resultados a ser alcanzados y 85 actividades a desarrollar con un presupuesto de 14 millones 476 mil dólares. De esta suma, el área de desarrollo y gestión de recursos humanos, coordinada por Brasil, concentró 10 millones 555 mil dólares, esto es, el 73\% del presupuesto total (pp. 36-43). Estos recursos procedieron del Ministerio de Salud de Brasil y de la Fundación Oswaldo Cruz (FIOCRUZ) (ISAGS, 2016a, p. 1).

Con respecto al ISAGS, pese a su creación en noviembre de 2009, la aprobación del estatuto tendría que esperar hasta abril de 2011, en ocasión de la IV Reunión Ordinaria del consejo 
(Resolución 02/2011 del CSS, 2011). El proceso de institucionalización, en cambio, concluiría en mayo de 2016, cuando la entonces presidenta de Brasil Dilma Rousseff promulgó la homologación del Acuerdo de Sede en Río de Janeiro. Solo a partir de entonces el ISAGS lograría el estatus de organismo intergubernamental (ISAGS, 2016a, p.1)².

El instituto planteó consolidarse como un centro de altos estudios y debate de políticas para la formación de cuadros estratégicos en salud, y actuar como institución facilitadora del trabajo del CSS y de la promoción del trabajo en red (Decisión para el Establecimiento del Consejo de Salud Suramericano de la UNASUR, 2008). Para ello, se empezaron a planificar múltiples talleres, cursos e investigaciones, y fueron creadas seis redes estructurantes. Estas redes serían integradas por "instituciones estructurantes de los sistemas de salud" y tendrían el compromiso de articulación de recursos humanos, promoción de cooperación técnica y desarrollo y mantenimiento de los "sistemas de monitoreo de la fuerza de trabajo y de la formación de personal" (Resolución 07/2009 del CSS, 2009). Las redes serían designadas por los ministerios de salud de los Estados miembros y, como señalaba el Estatuto del ISAGS, podrían formar parte de su consejo consultivo. Estas redes son: 1) la Red de los Institutos Nacionales de Salud (RINS); 2) la Red de Escuelas Técnicas de Salud de UNASUR (RETS-UNASUR); 3) la Red de Institutos Nacionales de Cáncer (RINC); 4) la Red de Escuelas de Salud Pública de UNASUR (RESPUNASUR); 5) la Red de Gestión de Riesgos y Mitigación de Desastres y; 6) la Red de Oficinas de Relaciones Internacionales y de Cooperación Internacional en Salud (REDSSUR-ORIS).

Esta impronta regional llamaría la atención de varios académicos, particularmente argentinos y brasileños, y quedaría reflejada en la publicación de distintos trabajos alrededor del CSS y del ISAGS identificados en el siguiente apartado.

\section{Pensamiento sanitario y políticas regionales}

\footnotetext{
2 En la literatura especializada es bastante usual encontrar la referencia a julio de 2011 como fecha de creación del ISAGS, no tanto así a noviembre de 2009. Ello se debe a que fue en ese entonces que se inauguró la sede del instituto en Río de Janeiro (Acta de la Reunión del Pro Instituto Suramericano de Gobierno en Salud (Pro ISAGS), 2011; Resolución 01/2011 del CSS, 2011), se designó como director ejecutivo al ex ministro de salud de Brasil José Gomes Temporão, y se constituyeron los consejos directivo y consultivo (Resolución 02/2011 del CSS, 2011; Resolución 03/2011 del CSS, 2011).
} 
Los estudios sobre UNASUR Salud y el ISAGS han sido desarrollados de forma notable, aunque no exclusiva, por parte de investigadores vinculados al proyecto de Reducción de la Pobreza e Integración Regional (RePIR) ${ }^{3}$ y de académicos que formaron parte directa o indirecta del cuerpo institucional del ISAGS.

Del proyecto RePIR destacan los estudios sobre UNASUR Salud bajo los enfoques de política social global, estudios regionales, diplomacia y política exterior (Amaya, Rollet y Kingah, 2015; Herrero, 2014; Herrero y Tussie, 2015; Riggirozzi, 2014, 2015a, 2015b, 2016; Riggirozzi y Grugel, 2016; Riggirozzi y Yeates, 2015). El grupo de autores vinculados al ISAGS, en cambio, centraron su atención en temas como el proceso de elaboración, implementación y estado de situación del Plan Quinquenal 2010-2015 (Garrón et al., 2012) y el rol estratégico de los institutos nacionales de salud de la UNASUR en la generación de conocimientos y facilitación de la toma de decisiones (Rosenberg, Tobar y Buss, 2015). De igual manera, éstos llevaron a cabo mapeos de los sistemas de salud (Giovanella et al., 2012a), de la vigilancia en salud (Carmo, Gemal y Oliveira, 2013) y de la atención primaria en salud en Suramérica (Giovanella, 2015; Giovanella et al., 2015), así como de otros análisis enfocados en el CSS y en el ISAGS como parte de la política exterior y de la cooperación internacional brasileña (Almeida et al., 2010; Buss y Ferreira, 2010; Buss, Ferreira y Hoirisch, 2011; Ventura, 2013).

Esta variedad de enfoques y abordajes fue más complementaria que excluyente. Ello quedaría claro en 2016, cuando se llevó a cabo en la sede del ISAGS un debate en el que participaron ambos perfiles de investigadores sobre los detalles técnicos y las posibilidades de implementación de un ejercicio de prueba para el monitoreo de las políticas de acceso a medicamentos en la región. ${ }^{4}$ En el plano teórico, por otro lado, pareció cada vez más frecuente el uso de conceptos característicos de la Economía Política Internacional anglosajona de tinte heterodoxa e institucionalista, tales como "salud global", "bienes públicos globales", "gobernanza

\footnotetext{
${ }^{3}$ El proyecto RePIR estuvo particularmente enfocado en la agenda de salud de la Comunidad de Desarrollo de África Austral (SADC, por su sigla en inglés) y de la UNASUR. http://www.open.ac.uk/socialsciences/prari/index.php?lang=es

${ }^{4}$ En abril de 2016 se llevó a cabo la reunión "Midiendo el progreso y el éxito de las políticas regionales de salud" en la sede del ISAGS en Río de Janeiro. La reunión estuvo organizada por miembros del proyecto RePIR bajo la coordinación de Pia Riggirozzi (ISAGS, 2016a, p. 2).
} 
global en salud" y "diplomacia en salud" (Almeida 2013, p. 233; Buss y Leal, 2009; Mazzaroppi, 2016).

La concepción de la salud como un derecho humano fundamental configuró el ideario conceptual y político del ISAGS. Como plataforma para la generación y difusión de conocimientos y formación de recursos humanos, el instituto promovió desde el inicio la construcción de un pensamiento sanitario suramericano. La formulación de estrategias y políticas regionales más inmediatamente operativas, en cambio, se mantuvo siempre como un reto.

Bajo el paraguas del ISAGS se llegaron a publicar varias contribuciones de especialistas vinculados en su momento al instituto y/o a organismos e instituciones públicas de la región, tales como la Fundación Oswaldo Cruz y la Agencia Nacional de Vigilancia Sanitaria de Brasil (ANVISA), y/o a los ministerios de salud y universidades de algunos Estados miembros. Se trata básicamente de los resultados de una serie de talleres y estudios.

Entre las publicaciones destacan tres libros. El primero presenta un mapeo de los sistemas de salud en la región que se titula precisamente Sistemas de Salud en Suramérica: desafíos para la universalidad, la integralidad y la equidad (Giovanella et al., 2012a). En este documento se retoman las ideas que sustentan el concepto de determinantes sociales de la salud elaborado en el marco de la Epidemiología Crítica. De ahí se defiende la necesidad de construir "sistemas públicos universales de salud" (concepción colectiva) y no de "aseguramiento universal" (concepción individual), que incluyan acciones sobre los determinantes sociales de la salud, la interculturalidad, el rescate de la medicina tradicional, la intersectorialidad de otras políticas sociales, así como la reducción de las desigualdades sociales (Giovanella et al., 2012b, pp. 5359; Giovanella et al., 2015; Temporão y Faria, 2014).

El segundo libro se titula Vigilancia en Salud en Suramérica: epidemiológica, sanitaria y ambiental (Carmo, Gemal y Oliveira, 2013). Este estudio exploratorio aborda desde distintas perspectivas el contexto, los componentes y la agenda de vigilancia en salud en la región, así como experiencias innovadoras y desafíos en Suramérica. Los autores presentan las propuestas consensuadas en los talleres del ISAGS que van desde el establecimiento de un marco conceptual común y de una política regional de vigilancia, hasta el apoyo a la articulación de grupos técnicos. 
El tercer libro, intitulado Atención Primaria de Salud en Suramérica (Giovanella, 2015), brinda un mapeo de esta cuestión en los doce Estados de la región. El texto recoge un análisis pormenorizado de la situación durante los últimos años a través de una metodología aplicada a cada país y desarrollada en ocho dimensiones: 1) conducción; 2) financiamiento; 3) prestación y organización; 4) coordinación de los cuidados e integración de la atención primaria de salud en la red de servicios; 5) fuerza de trabajo; 6) actividades intersectoriales; 7) participación social e; 8) interculturalidad.

Estos libros forman parte de un acumulado de estudios coordinados por el ISAGS en tanto el instituto desempañaba también las funciones de think tank regional en materia de salud. Estas publicaciones fueron complementadas con otras investigaciones en las que se sistematiza y describe información útil y pertinente, se realizan análisis comparativos entre los países suramericanos y se elaboran recomendaciones de acción conjunta. El listado identificado se muestra en la siguiente tabla:

Tabla 1. Listado de publicaciones en el marco del ISAGS (2012-2019)

\begin{tabular}{|c|c|c|}
\hline No. & Año & Título \\
\hline 1 & 2012 & $\begin{array}{l}\text { Sistemas de Salud en Suramérica: desafíos para la universalidad, la integralidad y la equidad } \\
\text { (Giovanella et al., 2012a). }\end{array}$ \\
\hline 2 & 2013 & $\begin{array}{l}\text { Vigilancia en Salud en Suramérica: epidemiológica, sanitaria y ambiental (Carmo, Gemal y Oliveira, } \\
\text { 2013). }\end{array}$ \\
\hline 3 & 2014 & $\begin{array}{l}\text { Mapeo de la capacidad productiva de medicamentos; políticas de medicamentos de los bloques } \\
\text { regionales: UNASUR, MERCOSUR, CAN, CARICOM Y ALBA, y mapeo de la cooperación bilateral } \\
\text { en producción y/o adquisición de medicamentos de los países de Suramérica (Azeredo, 2014). }\end{array}$ \\
\hline 4 & 2015 & Atención Primaria de Salud en Suramérica (Giovanella, 2015). \\
\hline 5 & 2016 & Taller de política de Salud de Fronteras en UNASUR (Restrepo, 2016). \\
\hline 6 & 2016 & $\begin{array}{l}\text { Mapeo de políticas de transferencia de ingresos y sus mecanismos de control y participación social } \\
\text { en los países miembros de UNASUR (Ninis, 2016). }{ }^{5}\end{array}$ \\
\hline 7 & 2016 & $\begin{array}{l}\text { As flexibilidades do TRIPS sobre propriedade intelectual: uma ferramenta para aprimorar o acesso } \\
\text { universal aos medicamentos essenciais (Fiani, 2016). }\end{array}$ \\
\hline 8 & 2017 & $\begin{array}{l}\text { Situación de medicamentos esenciales con riesgo de desabastecimiento con énfasis en los países } \\
\text { suramericanos (Acosta, 2017). }{ }^{6}\end{array}$ \\
\hline
\end{tabular}

${ }^{5}$ Este informe de investigación contó con la colaboración del Consejo Suramericano de Desarrollo Social. ${ }^{6}$ El "esfuerzo técnico" en la elaboración de este estudio no contó con la colaboración de los gobiernos de Argentina, Brasil, Guyana y Surinam (Acosta, 2017, p. 8). Se presume el creciente desinterés de los gobiernos de Argentina y Brasil en la UNASUR en general y en el Consejo de Salud en particular, así como la falta de información en materia por parte de los gobiernos de Guayana y Surinam por cuestiones financieras e institucionales. 


\begin{tabular}{|c|c|c|}
\hline 9 & 2017 & $\begin{array}{l}\text { Desafíos del envejecimiento poblacional para los sistemas de salud en Suramérica. Hacia el } \\
\text { envejecimiento saludable (Rígoli y Armada, 2017). }\end{array}$ \\
\hline 10 & 2017 & $\begin{array}{l}\text { Embarazo no-intencionado en adolescentes en América del Sur. Línea base sobre las políticas de } \\
\text { prevención e identificación de experiencias exitosas (Armada y Bacigalupo, 2017). }\end{array}$ \\
\hline 11 & 2017 & $\begin{array}{l}\text { Mapeo de las políticas de salud intercultural en Suramérica. "Todos somos diferentes. La igualdad } \\
\text { se construye" (Rígoli, Armada y Bacigalupo, 2017). }\end{array}$ \\
\hline 12 & 2018 & Compra pública de medicamentos en los países de UNASUR (ISAGS y SERCOP, 2018). \\
\hline 13 & 2018 & Mecanismos de participación social en salud en Suramérica (Armada, Iturria e Ignacio, 2018). \\
\hline 14 & 2019 & $\begin{array}{l}\text { Interferencia de la Industria de Alimentos en las Políticas de Etiquetado Gráfico Innovador de } \\
\text { Alimentos Procesados en Suramérica (Armada, Iturria y Bacigalupo, 2019). }{ }^{7}\end{array}$ \\
\hline 15 & 2019 & $\begin{array}{l}\text { Indicadores epidemiológicos prioritarios, factores de riesgo y determinantes sociales de las } \\
\text { enfermedades crónicas no transmisibles en Suramérica (Hage y Delgado, 2019). }\end{array}$ \\
\hline 16 & 2019 & Obesidad infantil: un desafío para superar la inercia po \\
\hline 17 & 2019 & américa (Ab \\
\hline
\end{tabular}

Fuente: Elaborado por los autores.

De forma paralela al desarrollo de estos estudios, durante la Semana de la Salud UNASUR, llevada a cabo en noviembre de 2016 en la Secretaría General en Quito, quedaría plasmado como uno de los mayores logros del ISAGS la conformación del Banco de Precios de Medicamentos de la UNASUR ${ }^{8}$. Este proyecto fue liderado por el Grupo de Acceso Universal a Medicamentos de la UNASUR (GAUMU) y logró concretarse tras años de negociación. El banco pretendía convertirse en una herramienta a disposición de los gobiernos suramericanos para comparar precios y aumentar así su poder de negociación frente a las grandes farmacéuticas. El propósito era simple: desarrollar estrategias conjuntas para generar ahorros que, en aquel entonces, se estimaban en cientos de millones de dólares anuales en la compra de medicamentos.

\footnotetext{
${ }^{7}$ De manera llamativa, el estudio señala que "[e]n todos los casos estudiados [Bolivia, Chile y Ecuador] se reportaron intervenciones por una parte de la industria de alimentos dirigidos a: impedir la aprobación de la implementación de las iniciativas de etiquetado, modificarla con el objeto de diluir su impacto o retrasarla" (Armada, Iturria y Bacigalupo, 2019, p. 33). Asimismo, se menciona que una parte de la industria de alimentos presentó obstrucciones durante el proceso de implementación de esta política en Perú y Uruguay. Los mecanismos de interferencia identificados fueron los siguientes: 1) negación de la necesidad y utilidad del etiquetado propuesto; 2) cuestionamientos técnicos; 3) consecuencias económicas desfavorables; 4) amplio uso mediático y; 5) otros posibles mecanismos (pp. 33-36).

${ }^{8}$ Esta iniciativa fue reconocida por Mariano Nascone, Director de Asuntos Sociales de la UNASUR (20152018), como el mayor logro del CSS en una entrevista realizada por los autores en febrero de 2019 en Quito.
} 
Hacia finales de 2017, el ISAGS señalaba: "el Banco está en marcha y los países ya empezaron a cargar información sobre los precios de medicamentos seleccionados, obtenidos en los contextos nacionales" (ISAGS, 2017a, p. 3). Y agregaba: "un total de 34 medicamentos y vacunas [han sido] identificados como responsables de altos gastos farmacéuticos" (ISAGS, 2017b, p. 7). Sin embargo, la autosuspensión de seis países miembros del organismo, en abril de 2018, frustraría todo intento de usar esta valiosa herramienta. Por otra parte, pese a los numerosos talleres, cursos, estudios y otras actividades llevadas a cabo por el ISAGS, difícilmente podría considerarse consolidada la pretensión del instituto de dar vida a "una corriente de pensamiento sanitario suramericano crítico que supere las fronteras del conocimiento habituales y avance en la construcción de sistemas públicos universales, integrales y equitativos en nuestra región" (Giovanella et al., 2012b, p. 65; ver también Giovanella et al., 2012a), menos aún el diseño y aplicación de estrategias y políticas comunes.

La iniciativa del Banco de Precios de Medicamentos se aprecia mejor cuando se la mira en un contexto más amplio. La promoción del acceso universal a medicamentos y el desarrollo de complejos industriales de salud reflejan las demandas históricas de numerosos Estados, en particular del ex Tercer Mundo, ante las grandes farmacéuticas. Concierne un tema clave de la cooperación Sur-Sur desde sus orígenes, pero se trata también de un sector que responde a los intereses de la industria de medicamentos, sobre todo genéricos, que tiene importantes representantes entre los miembros del grupo IBSA, es decir, de India, Brasil y Sudáfrica. Para el caso de Suramérica, destacan sin duda las pretensiones de Brasil de construir un Complejo Económico-Industrial de Salud (CEIS), como se revisa a continuación.

El CEIS ha venido siendo formulado desde inicios de los años 2000 por Carlos Gadelha, economista brasileño quien ha desempeñado cargos afines en el Ministerio de Desarrollo, Industria y Comercio Exterior, el ex Ministerio de Integración Nacional, el Ministerio de Salud y la FIOCRUZ durante los gobiernos del Partido dos Trabalhadores (PT). Para Gadelha, la construcción de este complejo se justifica en el histórico déficit comercial de salud que ha tenido Brasil y la consecuente amenaza tanto a la universalización de la salud garantizada en la constitución brasileña, esto es, el Sistema Único de Salud (SUS), como a los anhelos de inserción competitiva nacional en un ambiente globalizado. El rol del Estado en la conceptualización de este complejo ha sido central, lo cual explica en parte su eco notable durante los gobiernos de 
aspiración neodesarrollista de Lula da Silva. En efecto, el CEIS fue considerado como objetivo prioritario en la Política de Desarrollo Productivo lanzada en 2008 y como eje estratégico de planificación del Ministerio de Salud para el periodo 2008-2011 (Gadelha, 2003; Gadelha, Costa y Maldonado, 2012; Gadelha y Braga, 2016; Gadelha y Temporão, 2018).

La relación entre el acceso universal a medicamentos y su producción regional, como se ha mencionado, estuvo presente desde el inicio en la agenda de UNASUR Salud. Por ello, como acertadamente han señalado Herrero y Tussie (2015), el ISAGS planteó “identificar capacidades industriales existentes en la región para coordinar políticas comunes de producción de medicinas y otros bienes, avanzando la industria y creando ventajas competitivas en negociación global y provisión para la salud regional" (p. 271, traducción de los autores). Sin embargo, pese al desarrollo preliminar de un estudio, finalmente no fue posible realizar un mapeo de la capacidad productiva de laboratorios públicos y privados de la región por "dificultades administrativas y exceso de actividades de UNASUR" (Azeredo, 2014, p. 6). Más bien, se llevó a cabo un mapeo de políticas de medicamentos en la UNASUR, MERCOSUR, CAN, CARICOM y ALBA-TCP y otro de acuerdos bilaterales en producción y/o adquisición de medicamentos (2014). Thiago Azeredo, autor del estudio, también señalaba:

Iniciativas más relacionadas con el acceso, como el fomento a la producción pública de medicamentos, se reflejan en iniciativas de cooperación bilateral fuera de la región - en los proyectos de instalación de fábrica de medicamentos antirretrovirales en Mozambique (y Nigeria en estado más inicial), realizados en cooperación con Fiocruz (p. 26).

Si bien es cierto que la relación entre el CEIS y UNASUR Salud nunca fue formalizada, mucho menos se llegó a desarrollar una fase de regionalización, el giro político tras la asunción de Michel Temer en 2016 habría puesto en entredicho el proceso nacional de construcción de dicho complejo (Gadelha y Temporão, 2018, p. 1900).

\section{Posicionamiento ante la ASAmblea mundial DE LA SALUd}

Un resultado destacable del CSS, que indudablemente llegó a diferenciarlo de otros consejos sectoriales de la UNASUR, es el haber logrado presentar posiciones comunes, aunque sin 
conseguir una representación oficial, ante el principal foro multilateral en su materia: la Asamblea Mundial de la Salud de la OMS. ${ }^{9}$

Desde la $63^{\circ} \mathrm{AMS}$ en 2010 hasta la 69 AMS en 2016, los Estados miembros de la UNASUR presentaron un total de 35 posiciones comunes de las cuales 14 giraron en torno al tema de los medicamentos (ISAGS, 2017c, p. 9). De 2010 a 2014, los temas o resoluciones sobre los cuales los gobiernos de la UNASUR lograron consensuar una posición común, tuvieron que ver con cuestiones tales como la falsificación de productos médicos, el financiamiento de la OMS, la prevención y control de enfermedades no transmisibles o el acceso a medicamentos esenciales (Faria, Giovanella y Bermúdez, 2015, pp. 927-928). Riggirozzi saludó estos consensos manifestando que 'UNASUR busca reducir los riesgos sanitarios transfronterizos e 'intermediar' nuevas políticas, renegociando los términos de las políticas existentes en salud en foros internacionales vis-à-vis con las compañías farmacéuticas" (2014, p. 442, traducción de los autores). De acuerdo con la autora, la UNASUR habría asumido estos desafíos en tres niveles interrelacionados: uno institucional, otro dirigido por proyectos y otro diplomático (p. 443).

En ocasión de la $68^{\circ}$ AMS se presentó una posición común en torno a uno de los temas más relevantes de ese año: la salud en la Agenda de Desarrollo pos2015 (Faria, 2015, p. 343). La 69 AMS no sería la excepción, cuando se consensuaron posiciones en torno al informe presentado por el Grupo Consultivo de Especialistas en Investigación y Desarrollo (CEWG, por su sigla en inglés), la escasez de medicamentos pediátricos y el combate a los productos espurios, engañosos, falsificados o de imitación (SSFFC, por su sigla en inglés) (ISAGS, 2016b, p. 7).

Pese al acumulado de consensos alcanzados, esta dinámica se vería interrumpida en la $70^{\circ}$ AMS. Así, si bien a finales de marzo "[l]as delegaciones acordaron efectuar un documento proponiéndole a la OMS la inclusión de los cuatro temas correspondientes a las Declaraciones

\footnotetext{
${ }^{9}$ A diferencia de la Unión Africana, de la Comunidad del Caribe, del Sistema de Integración de América Central y de la Unión Europea, los cuales poseen posiciones de observadores permanentes en la OMS, la Unión de Naciones Suramericanas no alcanzó a ser reconocida como un bloque regional en esta organización. Es decir, UNASUR no logró tener una representación oficial en la AMS (Faria, Giovanella y Bermúdez, 2015, p. 925).
} 
aprobadas" (Acta de la X Reunión del CSS, 2017) ${ }^{10}$, a diferencia de los siete años anteriores, el CSS no llevó a cabo una reunión previa en Ginebra para consensuar posiciones.

Al mes siguiente, en un artículo de opinión de Salud al Sur, la revista del ISAGS, la entonces directora ejecutiva Carina Vance, señalaba:

El posicionamiento conjunto de los países en foros internacionales no es un objetivo en sí mismo, es un mecanismo que da fuerza a las propuestas de los países, y ha sido utilizado con mucha efectividad por parte de UNASUR. [...] No podemos desconocer la coyuntura política regional actual, pero esto no quiere decir que las posiciones particulares de los países sean marcadamente distintas entre sí. La salud es un eje integrador, común y con capacidad única entre los temas que prioriza UNASUR de llevarnos hacia una región unida y saludable (2017, p. 5).

Se rompía así un consenso importante alcanzado por UNASUR Salud, significando también, al menos en el corto plazo, el estancamiento de la "diplomacia en salud" a la que con mucho énfasis se refirieron distintos académicos (ver por ejemplo Herrero, 2014; Herrero y Tussie, 2015; Riggirozzi, 2014, 2015a, 2015b).

\section{EL EMPUJE BRASILEÑO}

La creación del ISAGS, y los avances en la "cooperación estructurante en salud" relacionados con la UNASUR, expresaron en la década anterior el intento de Brasil de proyectarse, regional y mundialmente, en el campo sanitario a través de la cooperación Sur-Sur. De acuerdo con varios expertos y altos funcionarios de la FIOCRUZ:

La concepción de "cooperación estructurante en salud" se basa fundamentalmente en el enfoque de "construcción de capacidades para el desarrollo". Este nuevo paradigma innova en dos aspectos en comparación con paradigmas anteriores: integra formación de

10 Las cuatro declaraciones a las que se hace referencia en el acta son: 1) Declaración sobre el Reconocimiento de las Enfermedades Catastróficas como Eventos de Alto Impacto Económico para los Sistema de Salud de UNASUR; 2) Declaración sobre la Política Suramericana de Salud Intercultural y Étnica; 3) Declaración sobre Estándares Mínimos de Equipos Médicos de Emergencia (EMT) y; 4) Declaración sobre el reconocimiento del Acceso Universal a la Salud (Acta de la X Reunión del CSS, 2017). 
recursos humanos, fortalecimiento organizacional y desarrollo institucional; y rompe con la tradicional transferencia pasiva de conocimientos y tecnologías. El nuevo enfoque propone explorar las capacidades y recursos endógenos existentes en cada país (Almeida et al., 2010, p. 28, traducción de los autores).

Como práctica política, la cooperación estructurante en salud de Brasil se ejecutó de manera importante, aunque no exclusiva, como una modalidad de cooperación técnica y triangular SurSur a través del Término de Cooperación 41 (TC 41-Programa de Cooperación Internacional en Salud). EI TC 41 fue financiado en su mayoría por Brasil y tuvo el apoyo político, técnico y administrativo de la Organización Panamericana de la Salud durante el periodo 2005-2015 (OPS, 2015). Más detalladamente:

En el año 2005, la OPS/OMS y Brasil firmaron el Término de Cooperación № 41 Programa de Salud Internacional (PSI), con el objetivo de desarrollar un programa de cooperación internacional en salud orientado al intercambio de experiencias, conocimientos y tecnologías disponibles en instituciones del campo de la salud pública en Brasil y en los países integrantes de la OPS/OMS con prioridad para América del Sur y los Países Africanos de Lengua Oficial Portuguesa (PALOP), en el marco de la Cooperación Sur-Sur con triangulación de la OPS/OMS, en el apoyo a la Agenda de Salud para las Américas y al Programa Estratégico de Cooperación en Salud PECS/CPLP/PALOP (p. 10, traducción de los autores) (ver Gráfico 1).

Gráfico 1. TC 41: Cooperación Sur-Sur con triangulación de la OPS/OMS 


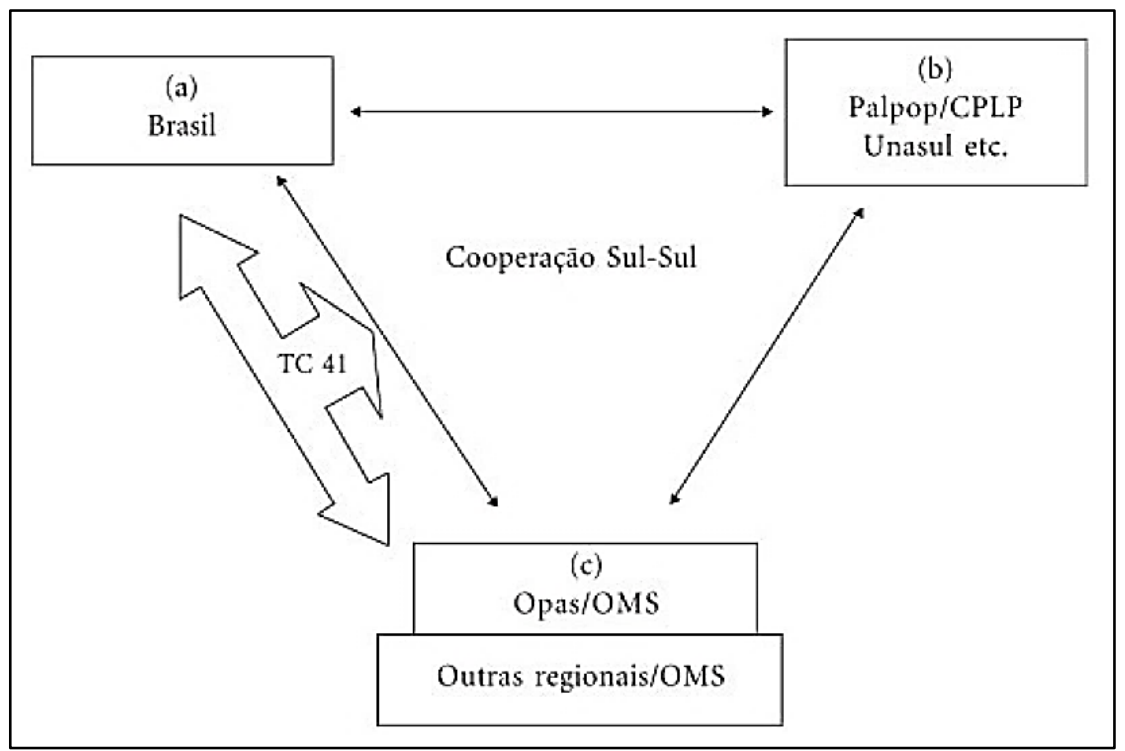

Fuente: OPS (2015, p. 11).

De acuerdo con la representación de la OPS en Brasil, el TC 41 se alineó "perfectamente" a las directrices de la política exterior brasileña en el campo de la salud, estableciendo un diálogo armónico y cercano entre los ministerios de salud y de relaciones exteriores y, en especial medida, con la Directriz 14 del Plan Nacional de Salud 2012-2015 de Brasil, la cual planteaba como objetivo la "promoción internacional de los intereses brasileños en el campo de la salud" (OPS, 2014, p. 44, traducción de los autores). En otras palabras, el TC 41 sentaba una "plataforma jurídica y operacional para el incremento y fortalecimiento de los procesos de cooperación internacional de Brasil" en el campo sanitario (p. 45, traducción de los autores).

Sin embargo, en el caso específico de Suramérica, la UNASUR estuvo involucrada en solo cinco de los 66 proyectos aprobados del TC 41 (OPS, 2014, p. 46; OPS, 2015, pp. 14-16). Tres de ellos se enfocaron en la creación de tres redes estructurantes: la Red de Escuelas de Educación 
Técnica de Salud ${ }^{11}$, la Red de Escuelas de Salud Pública de la UNASUR ${ }^{12}$ y la Red de Institutos Nacionales de Salud ${ }^{13}$, mientras que un cuarto proyecto planteaba el apoyo al desarrollo del ISAGS. ${ }^{14}$ Todos ellos fueron elaborados y coordinados por la Fundación Oswaldo Cruz. El quinto proyecto, en cambio, estuvo liderado por la Secretaría de Gestión de Trabajo y de Educación en Salud del Ministerio de Salud de Brasil y buscaba brindar apoyo al grupo técnico de recursos humanos de la UNASUR (OPS, 2015, pp. 13-16) ${ }^{15}$. En conjunto, estos proyectos fueron ejecutados entre 2009 y 2013 con recursos financieros aprobados por 2 millones 446 mil reales (pp. 24-26) ${ }^{16}$, una cantidad relativamente baja de los 43 millones 976 mil reales aprobados para el TC 41 (OPS, 2014, p. 46).

A manera de balance del programa en general, y de las redes estructurantes en particular, José Roberto Ferreira, cofundador y ex coordinador adjunto del Centro de Relaciones Internacionales en Salud de la FIOCRUZ, destacaba en 2015 que el mayor desacierto del TC 41, al menos hasta 2010, fue el haber financiado integralmente la cooperación con recursos del programa,

11 Creada en 2010, la RETS se encuentra a cargo de la Escuela Politécnica de Salud Joaquim Venâncio de la Fundación Oswaldo Cruz. El principal resultado de este proyecto habría sido la producción de una revista (Revista RETS) en español, inglés y portugués (OPS, 2015, pp. 118-119). No obstante, esta fue descontinuada por cuestiones operacionales en 2015, es decir, el año de finalización del TC 41, luego de haber publicado 22 números. http://www.rets.epsjv.fiocruz.br/es/revistas

12 Creada en 2011, la RESP fue coordinada por el Centro de Relaciones Internacionales en Salud (CRIS) de la FIOCRUZ. Los principales productos y legados de la red habrían sido la búsqueda de un diagnóstico de las capacidades formativas en salud pública en la región y la oferta de programas de posgrado (OPS, 2015, pp. 167-169).

${ }^{13}$ Creada en 2010, la RINS se encuentra a cargo de la CRIS-FIOCRUZ. Sus principales legados habrían sido la promoción de un espacio de diálogo, la transferencia de experiencias y el impulso al desarrollo de un pensamiento crítico (pp. 165-167).

${ }^{14}$ El objetivo de este proyecto fue apoyar el desarrollo del ISAGS "con la finalidad de planificar y programar actividades de investigación, innovación y capacitación de cuadros políticos y técnicos para la gestión de los sistemas y servicios públicos de salud de las Naciones que constituyen la UNASUR" (p. 170, traducción de los autores).

${ }^{15}$ Los principales resultados de este proyecto serían la formulación y aprobación del componente de recursos humanos en el Plan Quinquenal 2010-2015 del CSS, y la formalización de la RETS y de la RINS de la UNASUR (p. 112).

${ }_{16}$ De forma desagregada, los años de ejecución y los montos para cada proyecto fueron los siguientes: 496 mil 902 reales para la RETS (no se detalla el año ni en qué porcentaje estos recursos se dirigieron hacia la RETS-UNASUR y la RETS-PALOP); 750 mil reales en 2010 para la RINS; 800 mil reales en 2010 y 2011 para la RESP; 400 mil reales entre 2009 y 2010 para el apoyo al desarrollo del ISAGS y; 200 mil reales entre 2012 y 2013 de apoyo al GT de Recursos Humanos de la UNASUR (pp. 24-26). 
perjudicando la sostenibilidad de los proyectos al no promover la participación financiera de las contrapartes (OPS, 2015, pp. 75-76). Respecto a las redes estructurantes Ferreira señalaba:

La red es un intercambio entre las partes, y eso nunca hubo. La única relación que tenemos con cada miembro de la red es nosotros con ellos y ellos con nosotros. Entre sí no existe. De modo que no es red. Por otro lado, todas las actividades que se desarrollaron están dentro de ese concepto de red. No existe un proyecto de recursos humanos de un lado y red del otro, está todo dentro del mismo concepto, aunque la red es una propuesta teórica que no ha funcionado satisfactoriamente. [...] Creo que el error es nuestro. [...] La idea de la red es que los avances que ocurren en un país pudieran ser aprovechados por otros y viceversa. Entonces ellos se ayudarían entre sí, y no solo a nosotros. Esto reforzaría aún más el proceso de sostenibilidad. Esto no sucedió. Esto no sucedió en África y no está sucediendo en América del Sur (p. 76, traducción de los autores).

Los problemas en las redes estructurantes no se limitaron únicamente a aquellas instituidas bajo el TC 41. Walter Zoss, ex gerente ejecutivo de la Red de Institutos Nacionales de Cáncer de la UNASUR, una red estructurante creada en 2011 y dirigida por el Instituto Nacional de Cáncer de Brasil, señalaba en una entrevista de mediados de 2017:

Hay aspectos que no han funcionado bien en la Red. Un problema que solo ha ocurrido en algunos casos pero que es recurrente: la participación no siempre efectiva ni regular de los gobiernos en la RINC. Se observa discontinuidad y asimetría en la participación en las actividades, resultado, a veces, de los cambios naturales de gobierno o por la falta de priorización del control del cáncer en las políticas de salud pública de algunos de los Estados miembros (resp. 3).

Ahora bien, con base en la experiencia de las RESP, RINS y RINC de la UNASUR, Giovanni Agostinis ha argumentado desde una perspectiva liberal-institucionalista que:

Las instituciones regionales basadas en un sector, como UNASUR Salud, catalizan la difusión transnacional al permitir la interacción de las necesidades funcionales compartidas entre los Estados miembros y las capacidades asimétricas en áreas de política específicas. Lo hacen al reducir los costos de transacción y aumentar los 
intercambios de información entre expertos y profesionales estatales, lo que cataliza los procesos de aprendizaje interburocráticos que conducen a la difusión (2019, pp. 11111112, traducción de los autores).

El autor centra su análisis en la adopción voluntaria de recomendaciones de política sanitaria por parte de algunos Estados miembros, en ausencia de acuerdos vinculantes propios de una institución supranacional. Para Agostinis, el "proceso horizontal de internalización voluntaria" que habría ocurrido entre las escuelas e institutos sanitarios de algunos Estados miembros, al seguir un "patrón horizontal no jerárquico", sería el punto característico de esa "política de difusión transnacional" en UNASUR Salud mencionando, en particular, los casos de Colombia, Uruguay y Perú (2019, traducción de los autores).

Este tipo de análisis deja poco espacio para pensar en las relaciones de poder entre y al interior de los Estados miembros que pudieran haber empujado o no la adopción o creación de normas, políticas, programas e instituciones en materia de salud e incluso, a nivel político-diplomático, de aquellas dinámicas de presión de grupo entre los gobiernos de la región. Sobre todo, el "proceso horizontal de internalización voluntaria" y la "política de difusión no jerárquica" destacadas por el autor, difuminan la proyección regional e internacional de un país dentro de UNASUR Salud, es decir, de Brasil. No es casualidad que las redes analizadas por Agostinis sean coordinadas por el Instituto Nacional de Cáncer de Brasil y la FIOCRUZ, "la mayor institución en salud de América Latina" (Gayard, 2016, p. 144, traducción de los autores), ni que las experiencias apuntadas por el autor con Colombia, Uruguay y Perú hayan sido precisamente con Brasil y no con otro Estado miembro de la UNASUR.

En otras palabras, además de los problemas antes mencionados de las redes estructurantes, esta mirada teórica no parece tomar debidamente en cuenta los vínculos entre la cooperación Sur-Sur de Brasil, concebida como una herramienta de proyección internacional, y el Consejo de Salud de la UNASUR. Como acertadamente ha señalado José Paranaguá de Santana, entonces gerente del TC 41 de OPS Brasil, con este programa el Ministerio de Salud apuntalaba un protagonismo internacional acorde con los lineamientos de la política exterior brasileña, mientras que la representación de la OPS desarrollaba esfuerzos para acentuar su papel mediador en dicha cooperación internacional (OPS, 2015, pp. 11-12). 


\section{DE LA INERCIA AL COMA}

Después de 2015 el contexto regional ha sido marcado de manera creciente por una severa crisis económica y social y crecientes tensiones políticas entre gobiernos. Incluso, ya desde el primer mandato de Dilma Rousseff, se evidenció un menor interés y cambio de perspectiva en la política exterior y de cooperación internacional de Brasil (Gómez y Perez, 2016). El ISAGS, sin embargo, se mostró como una aparente excepción logrando continuar sus actividades con relativa fluidez. Esta particularidad, o excepcionalidad, fue observada por Gómez y Perez en estos términos:

El análisis de los actores y proyectos identificados sugieren dos procesos continuos en la PEB [(Política Exterior Brasileña)] en salud: uno en el que los recortes presupuestarios o los problemas de la PEB terminaron en peores resultados para los proyectos de salud; y otro en el que se pueden notar los cambios, sin embargo, la causalidad aún no está clara. [El segundo proceso se muestra] en los casos de los BRICS y de la Unasur, donde ha sucedido un declive, pero la inercia burocrática ha evitado peores consecuencias para los resultados de los asuntos de salud (p. 182, traducción de los autores).

Al centrar su análisis en actores y proyectos, los autores hacen referencia a una "inercia burocrática" que se habría venido desarrollando en la UNASUR en ausencia de "esfuerzos proactivos" durante el primer gobierno de Rousseff (p. 192, traducción de los autores). Ello explicaría en parte por qué solo en junio de 2019, es decir, en el contexto de disgregación del organismo y falta de financiamiento del instituto (Vance, 2019), el ISAGS habría decidido suspender sus actividades.

No cabe duda que, durante la última década, la UNASUR logró revitalizar positivamente la agenda regional en salud. Quedan registradas numerosas experiencias "hacia adentro", tales como la formación de una estructura institucional que propició el desarrollo de debates y estudios en materia sanitaria, así como la constitución de varias redes estructurantes. "Hacia afuera", por otro lado, destaca la presentación de posiciones comunes ante la Asamblea Mundial de la Salud. Pese a ello, la referencia a UNASUR Salud como a una "revolución silenciosa en la diplomacia en salud", ensalzada por Herrero y Tussie (2015, traducción de los autores), se volvió en un breve lapso no solo prematura, sino una clara exageración. 
La exacerbación de las diferencias político-ideológicas dentro de la UNASUR, tras la llegada de gobiernos de derecha, permite entender en parte la parálisis del Consejo de Salud previo a su defunción de facto (Riggirozzi, 2020). No obstante, no puede dejarse a un lado el menguante interés que el gobierno de Brasil, principal impulsor de esta agenda, venía manifestando con anterioridad, así como las restricciones presupuestarias del ISAGS, producto también de la desfavorable coyuntura económica en la región. En otras palabras, el ISAGS ya venía experimentando una paulatina, pero notable, disminución de su presupuesto anual. Y ello con independencia a la "amenaza" que para UNASUR Salud representaría la llegada de gobiernos neoliberales y conservadores (Herrero, Loza y Belardo, 2019, p. 845), incluso más allá de aquellos "límites", en palabras de Belardo (2018), como lo serían la toma de decisiones por unanimidad y la búsqueda de armonización de políticas públicas. En efecto, de un presupuesto de 4 millones de dólares aprobado para el periodo 2011-2012, el ISAGS pasó a disponer de 1 millón 999 mil dólares en 2015, para contar con apenas 216 mil dólares en 2018 (Resolución UNASUR/CD/P. RESOLUCIÓN/N 01/2012, 2012; Plan Operativo Anual y Presupuesto Detallado del ISAGS, 2015; Plan Operativo Anual y Presupuesto Detallado del ISAGS, 2018).

UNASUR Salud recibió el año 2019 en estado de coma. Era inducido para quienes hallaron la explicación de su parálisis en la llegada de gobiernos de derecha. Sin embargo, al dejar de lado cuestiones importantes tales como la falta de consenso para la adopción de estrategias y políticas comunes, los errores en el desarrollo de las redes estructurantes y el ascenso y declive del activismo internacional de Brasil, estas miradas resultan cuando menos parciales.

\section{A MANERA DE CONCLUSIÓN: ENTRE EL COVID-19 Y LA DESINTEGRACIÓN REGIONAL}

Cuando la OMS declaraba al nuevo coronavirus como pandemia en marzo de 2020, UNASUR Salud y el ISAGS se encontraban ya fuera de la contienda política. Si el panorama económico, político y social era desconcertante a nivel mundial, en la región era también aterrador. No era para menos, la CEPAL (2020, p. 7) lo expresaría sin cortapisas: "[l]a pandemia [...] conducirá a la peor contracción de la actividad económica que la región haya sufrido desde que iniciaron los registros, en 1900".

Mientras la virulencia del Covid-19 encontraba su caldo de cultivo en países con sistemas de salud anquilosados y cuyas estructuras de reproducción de la desigualdad y pobreza siguen 
siendo profundas (CEPAL y OPS, 2020, pp. 14-18), las reacciones iniciales de los gobiernos suramericanos fueron descoordinadas, sobre todo si se las compara con las de otras regiones y subregiones que cuentan con organismos regionales más establecidos (Barros, Gonçalves y Samurio, 2020).

El Foro para el Progreso de América del Sur (PROSUR), o "la farsa de una metamorfosis conservadora", como lo hemos denominado críticamente (Benzi y Narea, 2019), llevó a cabo reuniones virtuales que en el transcurso de los meses se revelarían como simples exhortaciones declarativas (Barros, Gonçalves y Samurio, 2020, pp. 132-134; Herrero y Nascimento, 2020; Rodriguez, 2020). La única excepción, hasta el cierre de este artículo, sería la liberación de una serie de patentes sobre tecnologías para combatir el Covid-19 (Rodriguez, 2020).

En otros espacios subregionales los acuerdos han sido similarmente magros. En el Mercado Común del Sur se movilizaron tempranamente recursos del Fondo para la Convergencia Estructural del MERCOSUR (FOCEM) por apenas 16 millones de dólares para el proyecto “Investigación, Educación y Biotecnologías aplicadas a la Salud" y, más recientemente, se habría impulsado la coordinación de estrategias entre el Instituto Social del MERCOSUR, ORASCONHU y OTCA (Herrero y Nascimento, 2020; Neves y Costa, 2020, p. 45; Ríos Sierra, 2020, pp. 215-216). En el marco de ORAS-CONHU de la CAN se reactivó la Red de Vigilancia Epidemiológica Andina, la cooperación en la vigilancia sanitaria en frontera y la articulación entre los institutos nacionales andinos de salud (Bressan, 2020, p. 27). En la Alianza del Pacífico, en cambio, no se conformó siquiera un grupo de alto nivel o técnico especializado en salud, relegando este tema de discusión para espacios como PROSUR y ORAS-CONHU (Naddi y Gonçalves, 2020, p. 33) ${ }^{17}$. Sin duda alguna, son las salidas unilaterales y los acuerdos bilaterales los que ostentan el protagonismo en la región (Herrero y Nascimento, 2020; Ríos Sierra, 2020; Rodriguez, 2020). O, como ha señalado recientemente José Briceño Ruiz, aunque, en otros términos, "los recursos aprobados por las instituciones regionales son limitados y los planes

17 Una vista panorámica sobre las respuestas de varios esquemas regionales a la pandemia ha sido presentada en el Dossiê - 2020. Regionalismo e Pandemia de Cadernos de Regionalismo ODR, coordinado por Mariano y Bressan (2020). Sus contribuciones, no obstante, dependen excesivamente de las fuentes oficiales de los organismos examinados y de instituciones afines, y no esbozan un análisis sobre su desempeño efectivo. 
están lejos de ser una política pública regional para hacer frente a la pandemia" (2021, p. 35, traducción de los autores).

Es tentador, pero probablemente desacertado, reflexionar sobre la llegada del Covid-19 a la región ante la hipotética existencia del Consejo de Salud y del ISAGS y, por extensión, de un organismo de cooperación intergubernamental como fue la UNASUR (Barrenengoa, 2020; Barros, Gonçalves y Samurio, 2020). Esas sugestiones, sin duda estimulantes para el debate político e ideológico, corren el riesgo de divagar en realidades alternas, pasadas y presentes, de escasa utilidad para el análisis social crítico. Ante el complejo momento histórico que se vive globalmente, tal vez resulte más apropiado preguntarse de modo franco y directo: ¿acaso la falta de un organismo regional como la UNASUR explica la ausencia de una respuesta común frente a la pandemia y, más aún, una respuesta eficaz para contener su virulencia? Aun si la respuesta fuera afirmativa, tal como parecen sugerir algunos expertos (Barros, Gonçalves y Samurio, 2020; Herrero y Nascimento, 2020; Riggirozzi, 2020), de momento no hay elementos suficientes para sustentar la idea de que políticas coordinadas regionalmente hayan sido más efectivas en la contención del contagio y en la gestión de la emergencia sanitaria. La situación en la Unión Europea podría darnos algunas pistas, en tanto fueron las respuestas nacionales (y nacionalistas) las que primaron en un inicio y, hasta la fecha, en cada pasaje delicado.

Lo que sí se puede afirmar con tranquilidad, en cambio, es que la potenciación de la crisis causada por el Covid-19 se convirtió en un factor adicional de desintegración y fragmentación en América del Sur (Barros, Gonçalves y Samurio, 2020). Es en este sentido que la descoordinación suramericana podría revelarse fatal, a diferencia de otras regiones con esquemas más institucionalizados y menos dependientes de las coyunturas políticas, en lo que con toda probabilidad será un largo y aún muy incierto periodo de recuperación. En este caso, estructuras como UNASUR Salud y el ISAGS podrían ser no solo bienvenidas, sino necesarias.

\section{REFERENCIAS BIBLIOGRÁFICAS}

Abreu, A. y Herrero, M. B. (Orgs.). (2019). El buen gobierno en salud: Miradas desde Suramérica. Instituto Suramericano de Gobierno en Salud; Facultad Latinoamericana de Ciencias Sociales. 
Acosta, A. (Coord.). (2017). Situación de medicamentos esenciales con riesgo de desabastecimiento con énfasis en los países suramericanos. Instituto Suramericano de Gobierno en Salud; Organismo Andino de Salud; Convenio Hipolito Unanue.

Agostinis, G. (2019). Regional Intergovernmental Organizations as Catalysts for Transnational Policy Diffusion: The Case of UNASUR Health. Journal of Common Market Studies, 57(5),

1111-1129. https://doi.org/10.1111/jcms.12875

Almeida, C. de. (2013). Saúde, política externa e cooperação sul-sul em saúde: elementos para a reflexão sobre o caso do Brasil. En Fundação Oswaldo Cruz (Ed.), A saúde no Brasil em 2030prospecção estratégica do sistema de saúde brasileiro: desenvolvimento, Estado e políticas de saúde (pp. 233-327). FIOCRUZ; IPEA; Ministério de Saúde; Secretaria de Assuntos Estratégicos da Presidência da República. https://saudeamanha.fiocruz.br/wp-content/uploads/2016/07/6.pdf

Almeida, C. de, Campos, R. P. de, Buss, P., Ferreira, J. R. y Fonseca, L. E. (2010). A concepção brasileira de "cooperação Sul-Sul estruturante em saúde". RECIIS. Revista Eletrônica de Comunicação, Informação \& Inovação em Saúde, 4(1), 25-35. https://doi.org/10.3395/reciis.v4i1.343pt

Amaya, A., Rollet, V. y Kingah, S. (2015). What's in a word? The framing of health at the regional level: ASEAN, EU, SADC and UNASUR. Global Social Policy, 15(3), 229-260. https://doi.org/10.1177/1468018115599816

Armada, F., y Bacigalupo, J. (Coords.). (2017). Embarazo no-intencionado en adolescentes en América del Sur. Línea base sobre las políticas de prevención e identificación de experiencias exitosas. Instituto Suramericano de Gobierno en Salud. https://docplayer.es/83089893-Nointencionado-del-sur-en-adolescentes-embarazo-en-america-politicas-de-prevencion-linea$\underline{\text { base-sobre-las-experiencias-exitosas-e-identificacion-de.html }}$

Armada, F., Iturria Caamaño, I. y Ignacio, C. (Coords.). (2018). Mecanismos de participación social en salud en Suramérica. Instituto Suramericano de Gobierno en Salud.

Armada, F., Iturria Caamaño, I. y Bacigalupo, J. (Coords.). (2019). Interferencia de la industria de alimentos en las políticas de etiquetado gráfico innovador de alimentos procesados en Suramérica. Instituto Suramericano de Gobierno en Salud. 
http://www.rets.epsjv.fiocruz.br/sites/default/files/arquivos/interferencia-de-la-industria-enetiquetado-isags.pdf

Azeredo, T. B. (2014). Mapeo de la capacidad productiva de medicamentos; políticas de medicamentos de los bloques regionales: UNASUR, MERCOSUR, CAN, CARICOM y ALBA, y mapeo de la cooperación bilateral en producción y/o adquisición de medicamentos de los países de Suramérica. Instituto Suramericano de Gobierno en Salud. https://www.alainet.org/fr/node/167329?language=en

Barrenengoa, A. (2020, 11 de Julio). El Covid-19 y la agudización de la fragmentación regional. El País. https://elpaisdigital.com.ar/contenido/el-covid-19-y-la-agudizacin-de-la-fragmentacinregional/27536

Barros, P. S., Gonçalves, J. S. B. y Samurio, S. E. (2020). Desintegração econômica e fragmentação da governança regional na América do Sul em tempos de COVID-19. BEPI. Boletim de Economia e Política Internacional, (27), 125-144. http://dx.doi.org/10.38116/bepi27art8

Belardo, M. (2018, 15 de febrero). Una década en la integración de Sudamérica: límites y perspectivas en salud. Sincopa. https://sincopa-sv.blogspot.com/2018/02/una-decada-en-laintegracion-de.html

Benzi, D. (2017). ALBA-TCP: Anatomía de la integración que no fue. Imago Mundi; Universidad Simon Bolivar.

Benzi, D. y Narea, M. (2019, 20 de marzo). ¿Y eso con qué se come? Prosur o la farsa de una metamorfosis conservadora. Desinformémonos. https://desinformemonos.org/y-eso-con-que-secome-prosur-o-la-farsa-de-una-metamorfosis-conservadora/

Bressan, R. N. (2020). Comunidade Andina e a pandemia de COVID-19. Cadernos de Regionalismo ODR, 4(1), 23-30. http://observatorio.repri.org/dossie/edicoes/vol-4-2020-ptdossie-a-atuacao-dos-blocos-regionais-em-meio-a-covid-19/ 
Briceño-Ruiz, J. (2021). Da crise da pós-hegemonia ao impacto da Covid-19. O impasse do regionalismo latino-americano. Cadernos de Campo: Revista de Ciências Sociais, 22, 21-39. https://periodicos.fclar.unesp.br/cadernos/index

Bortoni Ninis, A. (2016). Mapeo de políticas de transferencia de ingresos y sus mecanismos de control y participación social en los países miembros de UNASUR. Instituto Suramericano de Gobierno en Salud. https://docplayer.es/40819351-Mapeo-de-politicas-de-transferencia-deingresos-y-sus-mecanismos-de-control-y-participacion-social-en-los-paises-miembros-de-

\section{unasur.html}

Buss, P. y Ferreira, J. R. (2010). Diplomacia da saúde e cooperação Sul-Sul: as experiências da Unasul saúde e do plano estratégico de cooperação em saúde da Comunidade de Países de Língua Portuguesa (CPLP). RECIIS. Revista Eletrônica de Comunicação, Informação \& Inovação em Saúde, 4(1), 106-118. https://www.reciis.icict.fiocruz.br/index.php/reciis/issue/view/61

Buss, P., Ferreira, J. R., y Hoirisch, C. (2011). A Saúde Pública no Brasil e a Cooperação Internacional. Revista Brasileira de Ciência, Tecnologia e Sociedade, 2(2), 213-229. https://www.revistabrasileiradects.ufscar.br/index.php/cts/article/view/160

Buss, P. M. y Leal, M. C. (2009). Saúde global e diplomacia da saúde. Cadernos de Saúde Pública, 25(12), 2540-2541. https://www.scielo.br/scielo.php?script=sci issuetoc\&pid=0102$\underline{311 \times 20090012 \& \operatorname{lng}=p t \& n r m=i s o}$

Carmo, E. H., Gemal, A. y Oliveira, S. (2013). Caminos para avanzar: una agenda para el Siglo XXI. En E. Hage Camo, A. Gemal y S. Oliviera (Coords.), Vigilancia en Salud en Suramérica: epidemiológica, sanitaria y ambiental (pp. 213-221). Instituto Suramericano de Gobierno en Salud.https://www.researchgate.net/publication/258210315 Vigilancia en Salud en Surameric a epidemiologica sanitaria y ambiental

Comisión Económica para América Latina y el Caribe. (2020,). Dimensionar los efectos del COVID-19 para repensar la reactivación. Informe Especial COVID-19, (2). https://repositorio.cepal.org/handle/11362/45445

Comisión Económica para América Latina y el Caribe y Organización Panamericana de la Salud. (2020). Salud y economía: una convergencia necesaria para enfrentar el COVID-19 y retomar la 
senda hacia el desarrollo sostenible en América Latina y el Caribe [Informe COVID-19]. https://repositorio.cepal.org/handle/11362/45840

Consejo de Salud Suramericano de la Unión de Naciones Suramericanas. (2009, 21 de abril). UNASUR/Consejo de Salud Suramericano/Acuerdo $N^{\circ}$ 01/09-21/04/2009. UNASUR. http://bioeticaediplomacia.org/wp-content/uploads/2013/10/actaconsejo unasur 2009.pdf

Consejo de Salud Suramericano de la Unión de Naciones Suramericanas. (2009). UNASUR/Consejo de Salud Suramericano/Resolución 01/2009.

Consejo de Salud Suramericano de la Unión de Naciones Suramericanas. (2009). UNASUR/Consejo de Salud Suramericano/Resolución 05/2009.

Consejo de Salud Suramericano de la Unión de Naciones Suramericanas. (2009). UNASUR/Consejo de Salud Suramericano/Resolución 07/2009.

Consejo de Salud Suramericano de la Unión de Naciones Suramericanas. (2011). UNASUR/Consejo de Salud Suramericano/Resolución 01/2011.

Consejo de Salud Suramericano de la Unión de Naciones Suramericanas. (2011). UNASUR/Consejo de Salud Suramericano/Resolución 02/2011.

Consejo de Salud Suramericano de la Unión de Naciones Suramericanas. (2011). UNASUR/Consejo de Salud Suramericano/Resolución 03/2011.

Faria, M. (2015). Unasur Health Council: An emerging global actor in health policy and governance. Global Social Policy, 15(3), 341-344. https://doi.org/10.1177/1468018115600123c

Faria, M., Giovanella, L. y Bermudez, L. (2015). A Unasul na Assembleia Mundial da Saúde: posicionamentos comuns do Conselho de Saúde Sul-Americano. Saúde Debate, 39(107), 920934. https://doi.org/10.1590/0103-110420151070230

Fiani, R. (2016). As flexibilidades do TRIPS sobre propriedade intelectual: uma ferramenta para aprimorar o acesso universal aos medicamentos essenciais. Instituto Suramericano de Gobierno en Salud. http://www.rets.epsjv.fiocruz.br/biblioteca/flexibilidades-do-trips-sobre-propriedadeintelectual-uma-ferramenta-para-aprimorar-o 
Gadelha, C. A. G. (2003). O complexo industrial da saúde e a necessidade de um enfoque dinâmico na economia da saúde. Ciência \& Saúde Coletiva, 8(2), 521-535. https://doi.org/10.1590/S1413-81232003000200015

Gadelha, C. A. G. y Braga, P. S. C. (2016). Saúde e inovação: dinâmica econômica e Estado de Bem-Estar Social no Brasil. Cadernos de Saúde Pública, 32(2), 1-12. https://doi.org/10.1590/0102-311X00150115

Gadelha, C. A. G. y Temporão, J. G. (2018). Desenvolvimento, Inovação e Saúde: a perspectiva teórica e política do Complexo Econômico-Industrial da Saúde. Ciência \& Saúde Coletiva, 23(6), 1891-1902. https://doi.org/10.1590/1413-81232018236.06482018

Gadelha, C. A. G., Costa, L. S. y Maldonado, J. (2012). O Complexo Econômico-Industrial da Saúde e a dimensão social e econômica do desenvolvimento. Revista Saúde Pública, 46(1), 2128. https://doi.org/10.1590/S0034-89102012005000065

Garrón, K., Faria, M., Giler, G. Rojas Mattos, M. (2012, 3-7 de Diciembre). Análisis del proceso de la elaboración, implementación y estado de situación actual del Plan Quinquenal 2010-2015 del Consejo de Salud Suramericano-UNASUR [Ponencia]. Convención Internacional de Salud, Cuba Salud 2012. La Habana. http://actasdecongreso.sld.cu/index.php?P=GoTo\&ID=1317\&MF=4

Gayard, N. A. (2016). A cooperação Sul-Sul em saúde brasileira: Considerando conhecimentos, imaginários e práticas de uma política internacional [Tesis doctoral, Universidade Estatual de Campinas]. Repositório da Produção Científica e Intelectual. repositorio.unicamp.br/bitstream/REPOSIP/321446/1/Gayard NicoleAguilar D.pdf

Giovanella, L. (Org.). (2015). Atención primaria de salud en Suramérica. Instituto Suramericano de Gobierno en Salud. http://www.agr.una.py/descargas/biblioteca digital gestion riesgos/A/Atencion Primaria de la Salud.pdf

Giovanella, L., Feo, O., Faria, M. y Tobar, S. (2012). (Orgs.). Sistemas de Salud en Suramérica: desafíos para la universalidad, la integralidad y la equidad. Instituto Suramericano de Gobierno en Salud. https://issuu.com/isagsunasur/docs/sistemasdesalud 
Giovanella, L., Almeida, P. F. de, Vega, R., Oliveira, S. y Tejerina, H. (2015). Panorama de la Atención Primaria de Salud en Suramérica: concepciones, componentes y desafíos. Saúde em Debate, 39(105), 300-332. http://dx.doi.org/10.1590/0103-110420151050002002

Giovanella, L., Ruiz, G. Feo, O., Tobar, S. y Faria, M. (2012). Sistemas de Salud en América del Sur. En L. Giovanella, O. Feo, M. Faria, S. Tobar (Orgs.), Sistemas de Salud en Suramérica: desafíos para la universalidad, la integralidad y la equidad (pp. 21-69). Instituto Suramericano de Gobierno en Salud. https://issuu.com/isagsunasur/docs/sistemasdesalud

Gómez, E. y Aguilar Perez, F. (2016). A política externa brasileira em Saúde durante o governo de Dilma Rousseff (2011-2014). Lua Nova, (98), 171-199. https://doi.org/10.1590/0102-6445171$\underline{197 / 98}$

Hage, E., \& Delgado, Y. (2019). Indicadores epidemiológicos prioritarios, factores de riesgo y determinantes sociales de las enfermedades crónicas no transmisibles en Suramérica. Instituto Suramericano de Gobierno en Salud.

Herrero, M. B. (2014). El surgimiento de una nueva diplomacia regional en salud en tiempos posteriores al neoliberalismo: el caso de UNASUR Salud. Comentario Internacional, (14), p. 221252. https://repositorio.uasb.edu.ec/handle/10644/4594

Herrero, M. B. y Tussie, D. (2015). UNASUR Health: A quiet revolution in health diplomacy in South America. Global Social Policy, 15(3), 261-277. https://doi.org/10.1177/1468018115599818

Herrero, M. B., Loza, J. y Belardo, M. (2019). Collective health and regional integration in Latin America: An opportunity for building a new international agenda. Global Public Health, 14(6-7), 835-846. https://doi.org/10.1080/17441692.2019.1572207

Instituto Suramericano de Gobierno en Salud. (2015). Plan operativo anual y presupuesto detallado.

Instituto Suramericano de Gobierno en Salud. (2016a). ISAGS concluye el proceso formal de su institucionalización Informe ISAGS.

Instituto Suramericano de Gobierno en Salud. (2016b). Acceso a medicamentos domina posiciones comunes de la UNASUR. Informe ISAGS. 
Instituto Suramericano de Gobierno en Salud. (2017a). Un espacio de consenso. Salud al Sur, p. 3-5.

Instituto Suramericano de Gobierno en Salud. (2017b). La sombra del monopolio en la industria farmacéutica. Salud al Sur, p. 6-7.

Instituto Suramericano de Gobierno en Salud. (2017c). UNASUR en la AMS. Salud al Sur, p. 9. https://issuu.com/isagsunasur/docs/salud al sur maio 2017 esp digital

Instituto Suramericano de Gobierno en Salud. (2018). Plan operativo anual y presupuesto detallado.

Instituto Suramericano de Gobierno en Salud. (2011). Acta de la Reunión del Pro Instituto Suramericano de Gobierno en Salud.

Instituto Suramericano de Gobierno en Salud y Servicio Nacional de Contratación Pública de Ecuador. (2018, marzo). Compra pública de medicamentos en los países de UNASUR. https://subastademedicamentos.compraspublicas.gob.ec/publicaciones.html

Iturria, I. y Suárez, C. (2019). Obesidad infantil: un desafío para vencer la inercia política. Instituto Suramericano de Gobierno en Salud.

Jefes de Estado de la Unión de Naciones Suramericanas. (2008). Decisión para el Establecimiento del Consejo de Salud Suramericano de la UNASUR. http://www.itamaraty.gov.br/images/ed integracao/docs UNASUL/DEC.2008.CSS.PDF

Mariano, K. L. P. y Bressan, R. N. (Coords.). (2020). Dossiê -2020. Regionalismo e Pandemia: a atuação dos blocos regionais em meio à COVID-19. Cadernos de Regionalismo ODR, 4(1). observatorio.repri.org/wp-content/uploads/2020/11/Dossiê-2020-PT-arrumado.pdf

Mazzaroppi, E. (2016). Evolução histórico-conceitual da cooperação técnica internacional brasileira em saúde. RECIIS. Revista Eletrônica de Comunicação, Informação \& Inovação em Saúde, 10(3), 1-11. https://doi.org/10.29397/reciis.v10i3.1087

Ministros de Salud del Consejo de Salud Suramericano de la Unión de Naciones Suramericanas. (2009, abril). Agenda Suramericana de Salud. Plan de Trabajo 2009-2010. Reunión Constitutiva 
del Consejo de Salud Suramericano. https://docs.bvsalud.org/biblioref/2018/11/964135/2009 unasur plan trabajo 2009 2010.pdf

Ministros de Salud del Consejo de Salud Suramericano de la Unión de Naciones Suramericanas. (2017, 31 de marzo). Acta de la X Reunión de Ministros de Salud del CSS.

Organizaçao Panamericana da Saúde. (2014). Relatório de Gestão dos Termos de Cooperação. $1^{\circ}$ semestre de 2014. OPS-OMS; Ministério da Saúde de Brasil; Governo Federal do Brasil. https://iris.paho.org/bitstream/handle/10665.2/18435/relatorio\%20gestao\%202014 bra.pdf;sequ ence $=1$

Organizaçao Panamericana da Saúde. (2015). Avaliação do Programa de Cooperação Internacional em Saúde. Intercâmbio de experiências, conhecimentos e tecnologias entre instituições do campo da saúde publicano Brasil e nos países integrantes da OPAS/OMS. Organizaçao Mundial da Saúde. https://www.paho.org/bra/images/stories/GCC/avaliacao tc41 final.pdf?ua=1

Perello, C. (2019, 12 de junio). Entrevista a Carina Vance Mafla, directora del Instituto Suramericano de Gobierno en Salud. Nodal. https://www.nodal.am/2019/06/carina-vance-maflala-integracion-regional-depende-enteramente-de-la-voluntad-politica-de-los-gobiernos/

Restrepo, A. (2016). (Coord.). Taller Política de Salud de Fronteras en UNASUR. Instituto Suramericano de Gobierno en Salud. https://redeaps.org.br/wpcontent/uploads/2019/07/relatorio-fronteras-esp-final-30-03.pdf

Riggirozzi, P. (2014). Regionalism through social policy: collective action and health diplomacy in $\begin{array}{llll}\text { South America. Economy } & \text { 432-454. }\end{array}$ https://doi.org/10.1080/03085147.2014.881598

Riggirozzi, P. (2015a). UNASUR: construcción de una diplomacia regional en materia de salud a través de políticas sociales. Estudios Internacionales, 47(181), 29-50. https://revistaei.uchile.cl/index.php/REl/article/view/36837 
Riggirozzi, P. (2015b). Regionalism, activism, and rights: New opportunities for health diplomacy in South America. Review of International Studies, 41(2), 407-428. https://doi.org/10.1017/S026021051400028X

Riggirozzi, P. (2016). Regionalism and health policy in South America: Tackling germs, brokering norms and contesting power. In A. C. Bianculli, \& A. Ribeiro Hoffmann (Eds.), Regional organizations and social policy in Europe and Latin America. A space for social citizenship? (pp. 271-290). Palgrave Macmillan.

Riggirozzi, P. (2020). Coronavirus y el desafío para la gobernanza regional en América Latina. Análisis Carolina (12), p. 1-13. https://www.fundacioncarolina.es/coronavirus-y-el-desafio-parala-gobernanza-regional-en-america-latina/

Riggirozzi, P. y Grugel, J. (2016). Políticas de salud en UNASUR: legitimidad, democracia y legitimidad de resultado. Pensamiento Propio, (43), 173-200. http://www.cries.org/?p=3474

Riggirozzi, P. y Tussie. D. (2012). (Eds.). The rise of post-hegemonic regionalism. The case of Latin America. Springer.

Riggirozzi, P. y Yeates, N. (2015). Locating regional health policy: Institutions, politics, and practices. Global Social Policy, 15(3), p. 212-228. https://doi.org/10.1177/1468018115599819

Rígoli, F. y Armada, F. (2017). (Coords.). Desafíos del envejecimiento poblacional para los sistemas de salud en Suramérica. Hacia el envejecimiento saludable. Instituto Suramericano de Gobierno en Salud.

Rígoli, F., Armada, F., Bacigalupo, J. (Coords.). (2017). Mapeo de las políticas de salud intercultural en Suramérica. "Todos somos diferentes. La igualdad se construye". Instituto Suramericano de Gobierno en Salud. https://docplayer.es/80019140-De-salud-mapeo-deintercultural-las-politicas-en-suramerica-todos-somos-diferentes-la-igualdad-se-construyedeterminacion-social-de-la-salud.html

Rodríguez, C. (2020, 5 de noviembre). PROSUR frente al COVID. América Latina en Movimiento. https://www.alainet.org/es/articulo/209635 
Rosenberg, F., Tobar, S. y Buss, P. (2015). El papel de los institutos nacionales de UNASUR en la generación de evidencia sobre la determinación social de la salud. Revista Panamericana de Salud Pública, 38(2), p. 152-156. https://scielosp.org/pdf/rpsp/2015.v38n2/152-156/es

Sanahuja. J. A. (2008). Del "regionalismo abierto" al "regionalismo post-liberal". Crisis y cambio en la integración regional en América Latina. En L. Martínez Alfonso, L. Peña, \& M. Vázquez (Coords.), Anuario de la Integración Regional de América Latina y el Gran Caribe № 7, (pp. 1154). CRIES. http://www.cries.org/?page id=44

Temporão, J. G. y Faria, M. (2014). Reformas de los sistemas de salud en Sudamérica: una oportunidad para UNASUR. Revista Peruana de Medicina Experimental y Salud Pública, 31(4), 740-746. http://www.scielo.org.pe/scielo.php?script=sci arttext\&pid=S1726$\underline{46342014000400020}$

Unión de Naciones Suramericanas. (2012). UNASUR/CD/P. RESOLUCIÓN/ N 01/2012. http://www.itamaraty.gov.br/images/ed integracao/docs UNASUL/RES01.2012.pdf

Vance Mafla, C. (2017). Al punto. Salud al Sur, (7), p. 5.

Vance, C. (12 de junio de 2019). Entrevista a Carina Vance Mafla, directora del Instituto Suramericano de Gobierno en Salud. Nodal. https://www.nodal.am/2019/06/carina-vance-maflala-integracion-regional-depende-enteramente-de-la-voluntad-politica-de-los-gobiernos/

Ventura, D. (2013). Saúde pública e política externa brasileira. Sur. Revista Internacional de Direitos Humanos, 10(19), 99-117. https://bdjur.stj.jus.br/jspui/handle/2011/74595

Zoos, W. (12 de mayo de 2017). Integración latinoamericana para enfrentar al cáncer. América Latina en Movimiento. https://www.alainet.org/es/articulo/185432 
NAREA, MARCos: Master en Relaciones Internacionales por la Universidad Andina Simón Bolívar (UASB, Ecuador). Autor de ¿Regionalismo poshegemónico o contrahegemónico?: Una revisión de los debates teóricos actuales (UASB, 2020). Correo electrónico: marco.narea@gmail.com.

BenzI, DANIELE: Doctor en Ciencias, Tecnología y Sociedad por la Università della Calabria, Italia. Profesor visitante del Programa de Posgrado en Relaciones Internacionales de la Universidade Federal da Bahia, Brasil. Autor de ALBA-TCP. Anatomía de la Integración que no fue (UASB-Imago Mundi, 2017). Correo electrónico: danielebenzi@hotmail.com. ORCID ID: https://orcid.org/0000-0003-1340-1711 